\title{
The Role of the Information Society Model in Education in the United States
}

\author{
Ronald E. ANDERSON \\ University of Minnesota, rea@umn.edu
}

\begin{abstract}
"These lively debates over IT-related curriculum issues diverted the attention of educators from the challenge of investigating how best to apply the new technologies to helping students improve their learning."
\end{abstract}

\begin{abstract}
This critical appraisal of the role and impact of the information society model in the United States educational system begins with a discussion of three dominant paradigms: automation, "information society," and "mind tools;" and then traces the history of information and communication technology $(\mathrm{ICT})^{1}$ in education in the United States, describing how ideas, intertwined with the conceptions of the information society, led to distractions that have impeded vigorous development of ICT to improve education. These distractions included the claim that schools should take up the responsibility of training all students in ICT for the so-called information workforce. Promoters of the information society model together with the marketing arms of the IT industry perpetuated the adoption of ICT as an end in itself rather than as a means toward improving the main business of education, learning. These pressures over the past three decades have left the ICT in education in a state of confusion, lacking adequate support and, in many instances, the infrastructure to adapt to the demands of the twenty-first century.
\end{abstract}

Key words: Education, information society, information literacy

1 Although the acronym ICT is used extensively around the world, it can scarcely be heard in the United States. While the acronym IT (information technology) is commonplace in American business and government, the term "technology" is generally used within the educational system to refer to ICT or IT. In a few educational circles the word "edtech" is used instead. In this paper all of these acronyms and terms will be used interchangeably. 


\section{INTRODUCTION}

Compared with many other countries, the term "information society" is not often used in the United States and its publications, although ironically, the information society label is arguably more befitting North America than any other society today. Paradoxically, the United States pioneered the Internet and led most other countries in eCommerce, but it has been slower than many other technologically advanced countries in using the information society label. It would appear that the label "information society" could not be heard as much in the US because in the 1960s and 70s it came to be associated with those voices in the computer community emphasizing cautionary and negative implications of technology, namely the "computers and society" sub-community. In contrast, Japan fostered less negative voice on these issues and also pioneered use of the label [Kohyama, 1968]. Japan was the first country to use the information society as a justification in a major national policy document [Mashda, 1981]. The information society concept emerged in the USA primarily from analysis of economics and the nature of nonmaterial production. Outside the USA, e.g., Japan, there was more emphasis on the changing nature and role of media in society.

The information society metaphor is actually an archetype in that it captured the essence of an economy and culture dominated by ICT and associated information products, predating and anticipating the metaphor "knowledge society." The information society label was legitimated in the 1970 s and 1980s when economists were able to confirm that a majority of the jobs in the United States were information oriented, in that they were designed to produce informational rather than material products. In subsequent years, as global networks made discernible a global information economy, the information society metaphor became compelling, but it still did not catch on in the US, perhaps because of the promotion of the knowledge society concept by new industries promoting knowledge products.

\section{PARADIGMS OF ICT IN EDUCATION}

Before tracing how the information society concept permeated education in the United States, paradigms will be discussed that embody the dominant clusters of rationales, promises, and goals for using ICT in learning and teaching. The field of ICT and education is so heterogeneous in purpose, as well as function, that any in-depth critique requires some kind of focusing on goals in order to do justice to the intent of particular practices. 
Three largely competing paradigms are defined here, for the purposes of evaluating the state and impact of ICT in education. The three paradigms identified are (1) "automation," which seeks to reduce reliance on human teachers for the delivery of instruction using various types of machine-coded processes, (2) "information society," which subsumes all of the rationales for curriculum that relate to preparation of students for an evolving labor force oriented toward a global information economy, and (3) "mind tools," which refers to rationales that argue for technology applications that augment higher order intellectual functions and social or collaborative activity. While the three paradigms may sometimes overlap, they represent three distinct competing sets of priorities for ICT in education.

\section{Automation}

Programmed instruction (PI) began as an engineering discipline even prior to the emergence of the digital computer. With the guidance of stimulusresponse learning theory, procedures were designed to produce rote learning more efficiently. While it could be argued that such technology could save the teacher for other, more humane functions, another expressed aim was to offer cheaper teachers. The invention of digital processors gave birth to the field of computer-assisted instruction (CAI), which initially consisted of little more than transferring PI to the computer.

As the CAI field expanded into testing and instructional management, the labels and acronyms proliferated, e.g., computer-managed instruction (CMI) and computer-based instruction (CBI), a label that still persists today. These various sub-fields all came to be associated with "tutorials" and "drill and practice," what is now a negatively charged label among educators. The adherents to developing these technologies have adapted to the latest technologies today including multimedia and the Internet. Multimedia CBI, distance education (DE), and online learning (OL) all have their roots in the earlier instructional techniques and all purport to provide cheaper teachers. A substantial number of elementary schools have purchased integrated learning systems (ILS) that utilize programmed instruction aligned with learning objectives and assessments. These systems give the teacher better ways to track individual student progress. This approach is particularly popular for remedial instruction in basic subjects.

While the automation paradigm in education preceded the information society archetype, it has continued to retain a solid, if controversial share, of the edtech (educational technology) industry, as well as maintaining a role within school technology programs. Its most recent variant, distance education (DE), is promoted as offering educational and training opportunities needed by information and knowledge workers. 


\section{Information Society (IS)}

The information society (IS) paradigm is used here to refer to the goals, explicit and implicit, that impinge upon education in an information economy. Perhaps the greatest demand is the responsibility to train students for the information industry and other workforces utilizing information. This training encompasses ICT skills and other skills needed by workers in a global information economy. The IS paradigm is distinctive from the other paradigms in that its justification is not to improve student learning but to prepare the student for the workforce or the information economy outside of school.

In the 1960 s and 70 s the authors of computer-related texts were not likely to use the term "information society" but used the labels "information age" and "computerized society" instead [Martin and Norman, 1970]. The first textbook for the college-level "computers and society" course was published in 1972 [Rothman and Mosmann], but it did not mention the "information society". In 1979 Daniel Bell's "framework for the information society" gave academic legitimacy to the concept. In the early 1980s largescale electronic networks rapidly expanded providing physical representations that make the notion of the information society more compelling. Not surprisingly, numerous IT textbooks during the 1980s discussed the information society concept. For instance, Rosenberg [1986] included an entire chapter on social issues and called the chapter "Information Society." When the information society rhetoric was used in academic works, it most frequently referred to a general trend in restructured social institutions and lifestyles throughout society, but in more popular publications in came to be largely synonymous with IT and its culture. In the 1990s the phrases National Information Infrastructure (NII) and Global Information Infrastructure (GII) were used in discourse arguing for an expanded role of the Internet, which implicitly made the concept of the information society less and less an abstraction.

For at least two decades educators have tried to translate these information society concerns into curricula and instruction that addressed prevailing notions of what the workforce needed. Initially the emphasis was on computer literacy, then computer programming, followed by general productivity tools. As many students came to learn to use word processors, emailers, and browsers, at home, work, or on their own at school, the curriculum shifted toward information literacy as the central preparation for the so-called information society. Information literacy came to be broadly defined as use of collaborative tools as well as the core skills of web and database searching, with some attention to the critical evaluation of information. 
The topics most unique but central to the information society model are the social, legal, and ethical aspects of information work, but ironically they were often completely omitted from the ICT-related curricula or were mentioned briefly and discussed superficially. The one exception to this was the "computer and society" course that emerged in most university computer science programs, but was typically offered only for advanced majors in computer science.

As the IS paradigm was defined to be those objectives for ICT-related education intended to prepare students for life outside of school, this paradigm includes apprenticeships and other educational programs for particular occupations or tasks central to the information economy. Included here are computer science programs at both secondary and postsecondary institutions, management information system programs, and activities designed to prepare students to apply ICT tools in any number of occupational fields.

\section{Mind Tools}

The emphasis of this paradigm, like that of the automation paradigm, is upon using ICT for immediate in-school learning rather than for future jobs. But the emphasis is upon high-level thinking and problem solving on the one hand and upon teamwork and joint projects on the other. The roots of this paradigm lie in recent theory and empirical research in cognitive psychology, which concluded that learning environments should be studentfocused, assessment-focused, and knowledge-centered [Bransford, et al. 1999]. These conclusions largely overlap with the philosophy of instruction, called constructivism, that many education and edtech leaders support. The objectives subsumed here have been greatly facilitated by the National Science Foundation (NSF), which funded a number of projects that designed technologies to scaffold existing learning strategies or provide for new means of learning using ICT. Typical strategies developed include new modelling and visualization tools for specific mathematics and science problem solving.

The mind tools paradigm should not be confused with that of Jonassen's [2000] approach called "mindtools," although there are many overlapping elements. Jonassen promotes the use of specialized, advanced computer tools for problem-solving, improving understanding, and otherwise augmenting intellectual processes. He would not consider a word processor as one of his mindtools, however the use of a word processor to improve writing or compositional skills would be consistent with our mind tools paradigm.

Empowerment is at the core of this paradigm and one of the earliest programs to embody this approach was ESCOT, which was sponsored by 
Apple [Sandholts, Rignstaff, and Dwyer, 1997]. More recent variants of this philosophy have been espoused for higher education [Weigel, 2002] and life long learning [Shneiderman, 2002].

The mind tools paradigm is currently the most favored rationale for edtech among educational ICT leaders in the U.S.. The main argument for giving this paradigm priority is the growing body of cognitive research literature that confirms its superiority from the standpoint of pedagogy. Another argument used for this paradigm is that it is the most effective way to use scarce resources. Certain mind tools contain ICT-essential functions, e.g., dynamic modelling, that cannot be done in any other way. To the extent that their learning outcomes are pedagogically effective, mind tools add value to the educational process.

Word processing illustrates the distinctions among the three paradigms. Automation objectives foster the use of typing tutor programs and spelling drill software for giving students repetitive practice in basic skills of using a word processor. Information society objectives are fulfilled by vocational word processing training and by course work that gives students the ability to prepare documents in an ICT environment. Mind tool goals are achieved when students use a word processor to write papers for their classes or for producing intellectual products for other purposes. Even though any given ICT-based learning activity could be classified as predominantly intended to serve one of the three paradigms, it is also true that many learning activities could be seen as facilitating objectives associated with more than one paradigm.

\section{A BRIEF HISTORY}

Next the history of ICT in U.S. education is summarized in order to chart the emergence of these three paradigms and to show how some of the ideas of the information society infiltrated education.

\section{The 1970s}

The 1970s was the decade when the field of computers in education struggled to become established. In 1969 with funding from the NSF, the first general conference on digital technology and education was held. It was called Conference on Computers in Undergraduate Curricula (CCUC) and attracted an attendance of less than 100 persons. This conference was held annually for 10 years until 1979 when it was re-named the National Educational Computer Conference (NECC). By that time there were quite a few elementary and secondary educators active in supporting computer applications in education. It was not until the 1970s that timesharing and 
minicomputers became available and ultimately commonplace within the education sector. General productivity tools were scarce and so it was not surprising that the computer education or informatics curriculum, such as it was, consisted mostly of computer literacy and computer programming instruction.

This decade was the "hey-day" of automated approaches to edtech. Control Data started the Plato project that employed hundreds of software engineers pioneering techniques of $\mathrm{CAI}$ and $\mathrm{CMI}$ for the purpose of selling systems and system services, as well as courseware. The National Science Foundation gave enormous grants to Patrick Suppes to develop CAI, initially in mathematics and later in science and reading. This project spawned the start up of Computer Curriculum Corporation (CCC), which became one of the largest companies in the educational software and the ILS businesses. In addition to these two huge projects that dominated the field of $\mathrm{CAI}$, there were numerous smaller scale projects in both business and academe to design, refine, and sell CAI and its variants. During this time many teachers and professors discovered that their educational expertise could be successfully marketed, obtaining consultant and full time employment in this new, volatile industry. As timesharing, minicomputers and microcomputers all became reality during this decade, excitement, optimism, and entrepreneurial spirit were rampant within the rapidly growing community of educational technology specialists.

\section{The 1980s}

The 1980s was the era of the microcomputer and the personal computer (PC). By the end of the decade microcomputers were often connected within local area networks (LANs) and into large-scale networks such as Bitnet. During this decade the number of computer units in schools grew rapidly and many teachers were newly persuaded to incorporate computing into their teaching. Fierce competition emerged among software companies over their proprietary productivity tools, and some instructors became wealthy writing texts teaching how to use the more popular tools. Many teachers and their students were trained in using these tools as it was considered critical to the future of the economy for the incoming labor force to be skilled in these tools. Although neither developers nor teachers used the information society terminology, the IS paradigm was the driving force shaping curriculum and classroom during this decade.

At the beginning of the decade the fierce debates (in both public and private) over the definition of computer literacy, led to a common understanding by the middle of the decade that computer literacy was passé. Initially the debate was over whether or not the introductory computing courses (or course units) should include computer programming in BASIC 
or LOGO. Several prominent educational technology leaders left teaching for full time authoring of programming textbooks. But within a few years, powerful application packages for word processing, spreadsheets, and databases were widely available on personal computers, leading to the replacement of programming language instruction with application packages and their control languages. Text book authors and publishers jumped very rapidly on the bandwagon as the number of microcomputers soared and the potential for enormous profits in trade and text books, as well as educational software, became obvious. School curriculum supervisors defined their primary responsibility for the emerging information workforce to be training students in productivity tools, and academics intensely debated the priorities of these new curricula. At the middle school level, the debates were effectively squelched when the Texas Education Department, the first and largest textbook adoption auction, selected their top computer literacy textbooks. From that point on, requirements for the information society were institutionalized into K-12 education. During this decade, at least, the IS metaphor appears to have been over-driven by authors of textbooks, software developers, and the computer industry more broadly. The synergy between these various groups became apparent as textbook sales were fuelled by expanded sales of IT and vice versa.

These lively debates over IT-related curriculum issues diverted the attention of educators from the challenge of investigating how best to apply the new technologies to helping students improve their learning. Simultaneously, software developers were becoming millionaires almost overnight, enticing many to leave teaching and research jobs to try their hand at software and related ventures. Not only was this a serious brain drain on the budding field of educational technology, but these trends were all shifting intellectual focus away from trying to apply ICT to improve learning.

\section{The 1990s}

The 1990s decade was the decade of the Internet. Politicians, as well as educational practitioners, claimed magical outcomes from the Internet, and promoted private initiatives like Net Day and new public policy, such as the E-rate grants to schools, to pay for the high costs of the Internet. In the early part of the decade the Internet became widely used for file sharing and email. In the later years the World Wide Web (WWW) became a routine place for teachers and their students at all grade levels to look for information and to construct web sites. Handheld devices, such as personal data assistants (PDAs) became available and educators began to explore their use in teaching. As new legal and ethical issues piled up, a majority of the schools at all levels adopted an acceptable use policy (AUP), which was 
generally a statement of what ICT-related ethical responsibilities staff or students were expected to follow. As many students came to learn to use word processors, emailers, and browsers, at home, work, or on their own at school, there were attempts to shift the curriculum toward information literacy as the central preparation for living in the information society. Information literacy was increasingly defined to encompass use of collaborative tools as well as the core skills of web and database searching, and the critical evaluation of information. For the most part information literacy did not achieve a place in the curricula. Instead teachers were expected to address, on an as-needed basis, how to critically evaluate Internet-based information, how to avoid inappropriate web-based material, as well as other social, legal, and ethical aspects of information work.

In many ways the 1990 s were parallel to the 1980 s in terms of radical transformation due to a new technology, this time the Internet instead of the PC. While the technology of interest shifted to the web, and ICT-related teaching shifted to web-site use and design, many of the best younger educators left for jobs in Internet and web businesses. The enormous cost of building an infrastructure for Internet access caused policy-makers and other stakeholders to question the payoff of technology in learning. They called for research that would show that payoff, but few researchers and evaluators were left. And the amount of funding available for research and accountability studies had been so low for many years, that answers were essentially impossible to produce.

\section{TODAY'S IMPLEMENTATION REALITIES}

Shifting from a historical focus to an understanding of the current state of education with respect to technology, we examine today's realities in terms of what we call "implementation goals," because they are relevant no matter which rationale or paradigm one subscribes to. These cross-cutting goals include: (1) access adequacy, relative to the infrastructure; (2) skilled ICT users, especially teachers and students; (3) supportive organizational climate (technical and instructional) for these users; (4) ethical climates that minimize unethical and illegal use of ICT; and (5) equity in digital benefits, which includes access and skill to use ICT. After reviewing contemporary fulfilment of these implementation goals, we will look at the future and return to the role and impact of the information society model on education.

\section{Access Adequacy}

The overall contemporary picture appears remarkable when viewed from an historical perspective. Whereas in 1970 only universities and some colleges 
had computers, within thirty years essentially all 150,000 schools had not only computers but Internet connections, and they were using and supporting ICT for instruction. By the year 2000 secondary schools had an average of 3 students for every instructional computer and essentially every school had access to the Internet. From this glimpse of the infrastructure growth, it would seem that the infrastructure is in good shape. To some extent that is true, however, K-12 schools still are a long way from providing adequate, up-to-date ICT for all teachers and students. Many teachers as well as students essentially lack access because the competition for resources is too great, the equipment is in disrepair or obsolete, the machine(s) have little usable software, no tech support is available to help them, they lack the skills to use the technology, or all of the above. Even for a large share of those who do have physical access to computers or the Internet, neither the human capital nor the social capital is sufficient to provide for effective utilization.

Obsolescence is still a major problem in schools, although it is less of a problem than 10 years ago when the majority of school computers were Apple II computers of 1970 s vintage. Most business and governmental organizations currently have a computer replacement cycle of about 5 years, whereas for schools it is approximately 10 years. In 1998 as much as $40 \%$ of the installed base of computers consisted of units that could not run multimedia programs because they lacked both sound capability and a CDROM drive [Anderson and Ronnkvist, 1999].

There are a myriad of additional obstacles that result in low access and use. For instance, one school studied by Means et. al. [2002] and her associates could not acquire more computers for classrooms because security costs were so high. For any classroom with computers, they had to install bars on the windows, replace the door with a special, secure door, and install surveillance cameras. Anecdotes of this type from many sources [cf. Stoll, 1995] indicate that school administrators often do not have the knowledge or resources to deal with thefts and other security problems. Technical malfunctions (in either hardware or software) can produce a similar impasse when the school lacks adequate technical support. These are two of the major reasons for high rates of equipment non-use, which includes local networks and Internet connections.

\section{Skilled ICT Users (Teachers and Students)}

Little data are available on the skills of students, much less teachers, to adequately use ICT in their work. One exception is the IEA Computers in Education Study in 1992 [Anderson, 1993; Pelgrum et al, 1993]. They found that students in the USA performed significantly lower than those in Austria and the Netherlands in terms of "computer fitness," a fairly low- 
level test measuring what some would call "computer literacy" or IT "fluency". The US was relatively low compared to other technologically advanced countries on such indicators largely because its school system is highly decentralized. Countries with nationally centralized educational systems can generally establish and enforce curriculum changes more rapidly. The problem is not just that learning opportunities in ICT skills are generally not found in the curriculum, but it also is the case that many students who want or need the technology are not able to access it.

In 1998 the Teaching, Learning, and Computing (TLC) study conducted a national survey of over 4,000 randomly selected elementary and secondary teachers [Becker, 1999]. In that year $90 \%$ of the schools and a large share of the classrooms had Internet access. Nevertheless, the survey found that $27 \%$ of the teachers did not access the Internet at either home or school and only $39 \%$ reported classroom use of the Internet. Some groups of teachers, for example, math teachers, used computers and the Internet far less in or out of class than the average. While the share of teachers using the Internet reflected to some extent the lack of convenient equipment and network access, the survey found that the lack of skill in using the Internet was an important factor inhibiting its use [Becker, 1999].

Teachers need not only technical skills but skills in using ICT effectively pedagogically. The TIMMS Video Study in 1995 revealed how some teachers need guidance in this area. The TIMSS (Third International Mathematics and Science Study) classroom study videotaped over 1508 th grade mathematics classrooms in the US and Japan during the 1994-95 school year. They found that Japanese teachers, compared to American teachers, were more likely to use methods for teaching "deep understanding," as defined by the Authentic Achievement Project of Newmann and associates. The study also found that American classrooms had many more outside interruptions. The videotapes showed some American teachers giving their students trivial computer tasks, i.e., work that could be done more quickly with a calculator or an encyclopedia. One video showed the students stepping from one sheet of paper to another to illustrate how binary bits move around inside the computer microprocessor. This does not seem like a productive way to use classroom time in a middle school computer class, much less an algebra class. Some schools have reduced such limited classroom activities by setting up teacher mentoring programs dealing extensively with ICT issues.

\section{Supportive Organizational Climates}

Several reports from the TLC study have identified organizational attributes that played major roles in facilitating and inhibiting the integration of ICT into the classroom activities of a large share of a school's teachers 
[Ronnkvist, Dexter, and Anderson, 2000; Anderson and Dexter, 2001; and Anderson and Becker, 2001]. These investigations found that schools' commitments to technology investments, strong technology leadership, and the widespread availability of technology support for teachers all were strongly associated with technology integration. Without these organizational climates, a school was not likely to have integrated technology, as measured by the use of a variety of technology applications by a large share of teachers. Furthermore, the study found that it wasn't just a commitment to any technology spending that made a difference, but spending on software and support services were the most important investments contributing to greater technology integration.

There are relatively few indicators and almost no data on these organizational climates: financial commitments for technology, technology leadership, and technology support. The most comprehensive national study of school technology financials was the TLC school-level study in 1998. The conclusion was that the average school spent only $\$ 113$ per year per student on technology (including support services), which was $2.7 \%$ of total educational expenditures for that year. Of the total $\$ 113$ per student, only $\$ 8$ was spent on software, $\$ 22.50$ on support, and the remainder on hardware. While about $\$ 30$ per student was spent on software and support, the consensus of the technology coordinators themselves was that about twice that amount ( $\$ 60 /$ student) should be spent on software and support. We can infer from that set of findings that neither the technology support climate nor the technology leadership climate were adequate, as the hardware dollars have been over dominating the technology acquisitions and spending climate.

\section{Ethical Climates}

IT, and the Internet in particular, link students to the world outside the classroom and this poses one of the biggest problems. Students left to their own whims can access material on the Internet that most of their parents consider inappropriate or objectionable. Through the Internet, students can also break laws by using copyrighted material or by illegal entry into databases and computer systems. Many schools have responded to concerned parents by installing filtering or blocking software. Nevertheless, even schools that have such electronic mechanisms in place still must find effective ways to teach and encourage students and teachers to engage in responsible ICT behavior.

Most schools in the United States have responded to these challenges by instituting an Acceptable Use Policy (AUP). Often students, and sometimes parents, are asked to sign a version of the AUP which states that the signer agrees to follow acceptable uses and avoid unacceptable behaviors with 
respect to ICT, and the Internet in particular. In her study of school Internet activity, Schofield and Davidson [2002] found that many signers had not read the AUP and many students were aware of other students who had not followed the acceptable use guidelines.

Given that these mechanisms, both electronic and administrative, do not solve all of the emergent problems, it is important that a school organization creates a climate of ethical and social responsibility in general. While the administrative leadership of the school should address this challenge and take steps to create and develop supportive climates, involvement of the entire school community is needed to maintain the climate. Filters and AUPs are useful, but attitudes and values of all involved are important too, especially in adapting to new ethical issues that arise as the technology evolves and changes.

\section{Equity in Digital Benefits}

Many of America's 46 million public school students remain largely unaffected by the existing technological infrastructure. Huge numbers of teachers and students never touch a computer. Even while it is true that computers outnumber teachers, most teachers lack convenient access to them because student computer labs house the majority of the schools' equipment. Many schools have so few computers that they tend to be used only by small, elite groups of students or teachers.

During the last few years of the 1990 s, considerable attention by both local and national policy-makers was given to reducing the so-called digital divide, which initially referred to gaps in access to digital technology, especially computers and the Internet. The Anderson and Becker national survey in 1998 found that average per student expenditures on technology were about twice as much at schools in high-income, as in low-income communities. Numerous surveys earlier had shown substantial digital divides: that students from low-income or high-minority communities were much less likely to have access to computers or the Internet from home than those in other communities. However, more recent surveys have detailed how such gaps have been declining but not disappearing. In fact, the general pattern is that digital gaps remain high for the initial period of diffusion of new digital technologies. The literature on the digital divide in the past two years has noted a variety of different types of digital divide, particularly those that have to do with the quality of technology use and the skills to use them. 


\section{TOMORROW'S REALITIES}

\section{The Beginning of the 21st Century}

The remarkable patterns of repeated, major innovations in dominant ICTs for education during the past three decades necessarily leave us timid about predicting the future, even for five years in advance. What we have seen in the first few years of the current millennium is steady growth in the quantity and quality of educational applications, especially related to the Internet. A recent national survey by the Pew Internet and American Life Project [2002] found that $78 \%$ of children between the ages of 12 and 17 used the Internet and $98 \%$ of these had used it for a school research project.

The same Pew Internet study, using a very different methodology, probed focus groups of students in the 12 to 17 age range on their thoughts about Internet use in school. The study found that Internet-savvy teenagers were saying that "educators often don't know how, don't want, or aren't able to use online tools to help them learn or enrich their studies." The report argued that the nation's multi-billion dollar effort to wire schools is at risk of being squandered because there is not a similar commitment "to improve connectivity in classrooms, help all students master computer skills, teach more sophisticated Internet literacy, make sure that high-quality information is available to them, and - most important of all - create assignments that take advantage of the wonderful Web resources they have found on their own." Most teens claimed that "their Internet use occurs mostly outside of the school day, outside of the school building, and outside of the direction of their teachers." Students even claim that more engaging Internet activities would improve learning.

It would appear that in many ways Internet utilization among children and adolescents is outpacing that of adults. If nothing else, these trends suggest rapidly growing pressures of children on teachers and schools for better accommodation of their ICT-related learning needs.

\section{Twenty-First Century Standards}

Another very different trend is a shift in what government policy-makers and industry representatives perceive as the needs of the evolving "information society" labor force. In the past five years a number of special study commissions such as The $21^{\text {st }}$ Century Workforce Commission [2000] have issued white papers on "twenty-first century standards." These standards describe what students should be able to do upon graduation. They depart from earlier standards in that they no longer emphasize information and technology skills but instead stress skills in thinking, knowledge management, and communication. These new sets of standards 
suggest that greater value in the future likely will be placed upon abilities to construct knowledge and think creatively. These new standards also seem to reflect a relaxation of pressure upon schools to train students in ICT skills.

\section{Goals for Effective Technology Use}

Our earlier analysis demonstrated how the purposes for ICT have evolved in accord with the technological capabilities available, the conventional wisdom and other pressures on how best to utilize that capability, and the priorities given to alternative goals or paradigms. The twenty-first century white papers suggest that the future will experience less (or perhaps a different) influence by the information society model, and that there may well be greater focus on the approaches of the mind tools paradigm, especially greater emphasis on complex thinking and achieving deep understanding.

Critics such as Cuban [2002] and Hodas [1996] have objected to the high cost of the technology going into schools, to the neglect of other societal priorities. However, our portrayal of today's implementation realities has shown that while some policies have not been well thought out, the investment generally has not been nearly enough. If informationoriented industries and government agencies are taken as models for the role of ICT in schools, then schools fail miserably, especially in terms of IT support services. Ironically, education is one of the most informationoriented industries in modern society, and yet the expenditures for technology of about $2.5 \%$ of total expenses are about the lowest of all information industries.

Our critical analysis suggested that the information society model provided fuel, or an advocacy base, for a hegemony of diverse commercial interests steering education away from its prime mission of maximizing learning by technology and whatever other tools can best facilitate that process. This concert of forces also succeeded in duping education into sometimes treating ICT as an end in itself. Education will probably take some years to get over this corrupted sense of values.

The current popularity of distance education, which is heavily shaped by the tradition of the automation paradigm, indicates that education has been caught up in the fun and excitement of this new activity without taking adequate time to be accountable and investigate its social and educational impact. Brown and Duguid [2000] offer an exemplary analysis of the role of community in learning, which should serve as a framework guiding serious research in this area in the future. 


\section{CONCLUSIONS}

Cuban [2002] attributes technologically oriented reform measures in education to a "coalition of corporate executives, public officials, parents, academics and educators." In general he claims that "computers for the classroom have been oversold by promoters and policymakers and underused by teachers and students." While there are traces of truth in his claim, a more appropriate conclusion is that educators have not been given a clear, compelling mission for technology nor have they received the support and, in many cases, the infrastructure to carry out that mission.

An historical analysis of the role of goal paradigms on the state of ICT in education has revealed some weaknesses associated with each. The automation tradition has over emphasized teacher displacement and failed to address advances that would facilitate the learning of highly complex cognitive tasks. The information society tradition became commercially entangled and has over-emphasized the training of students for information jobs, especially lower-level occupations. The mind tools tradition requires much more research and creative development than it now receives.

\section{REFERENCES}

Anderson, Ronald E. (1998), Human and social issues in the age of informatics. In Tinsley, David and Johnson, David C. (eds), Information and Communications Technologies in School Mathematics (IFIP TC3/WG3.1 Working Conference), pp. 237-246. London: Chapman and Hall.

Anderson, Ronald E. and Becker, Henry Jay (2001), School Investments in Instructional Technology, Report \#8. Irvine, CA: Univ. of California [Available online at http://www.crito.uci.edu/TLC/findings.html]

Anderson and Ronnkvist, (1999), The presence of computers in American schools.

Report \#2 Irvine, CA: Univ. of California [Available online at http://www.crito.uci.edu/TLC/findings.html].

Anderson, Ronald E. and Dexter, Sara (2001), School technology leadership: Incidence and impact. (Teaching, Learning, and Computing, 1998, Report \#6), Irvine, CA (http://www.crito.uci.edu/tlc/findings.html).

Becker, H. J. Ravitz, J. and Wong, Y. (1999), Computer and software use by teachers. [Available online at http://www.crito.uci.edu/TLC/findings.html]

Bell, Daniel (1979), The social framework of the information society, pp 163-211, in Dertouzos, Michael L. and Moses, Joel (eds), The Computer Age: A TwentyYear View. Cambridge, MA: The MIT Press.

Bereiter, Carl (2000), Education and Mind in the Knowledge Age. (800 page manuscript at http://csile.oise.utoronto.ca/edmind/edmind.html).

Bransford, John D., Brown, Ann l. and Cocking, Rodney R. and Pellegrino, J. W.(1999), editors. How People Learn - Bridging Research and Practice, Washington DC: National Academy Press (www.nap.edu). 
Brown, John Seely and Duguid, Paul (2000), The Social Life of Information. Cambridge, MA: Harvard University Business School Press.

Cuban, Larry (2001), Oversold and Underused: Computers in the Classroom. Cambridge, MA: Harvard University Press.

Hodas, Steven (1996), Technology refusal and the organizational culture of schools. pp 197-218, in Kling, Rob (ed), Computerization and Controversy: Value Conflicts and Social Choices, 2nd edition. San Diego, CA: Academic Press.

Jonassen, David H., Computers as Mindtools for Schools - Engaging Critical Thinking, $2^{\text {nd }}$ Edition, Merrill, Prentice-Hall, Upper Saddle River, New Jersey, 2000.

Kohyama, Kenichi (1968), Introduction to information society theory, Chuo Koron (Winter 1968).

Martin, James and Norman, Adrian R. D. (1970), The Computerized Society. Englewood Cliffs, NJ: Prentice-Hall, Inc.

Masuda, Yoneji (1981), The Information Society as Post-Industrial Society. Bethesda, MD: World Future Society.

Means, Barbara, Penuel, William R. \& Padilla, C. (2001), The Connected School Technology and Learning in High School. San Francisco: Jossey-Bass.

National Research Council. Being Fluent with Information Technology. Computer Science and Telecommunications Board, Washington DC: National Academy Press (www.nap.edu), 1999c.

Newmann, Fred M. and Associates (1996), Authentic Achievement - Restructuring Schools for Intellectual Quality. San Francisco, Jossey-Bass Publishers.

Norris, Cathleen, Elliot Soloway, and Terry Sullivan (2002), Examining 25 years of technology in U. S. education, Communications of the $A C M 45,8$ (August), pp 15-18.

Panel on Educational Technology. (1997), Report to the President on the Use of Technology to Strengthen K-12 Education in the United States. Washington DC: President's Committee of Advisors on Science and Technology.

Pellegrino, James, Chudowsky, Naomi, and Glaser, Robert (Editors), Knowing What Students Know: The Science and Design of Educational Assessment. Washington DC: National Academy Press.

Pew Internet and American Life Project (2002), Digital Disconnect: The widening gap between Internet-savvy students and their schools. http://www.pewinternet.org/reports/pdfs/PIP_Schools_Internet_Report.pdf

Quality Education Data. (1999), Technology in public schools 1998-99. Denver, Colorado: Quality Education Data, Inc. (QED).

Rosenberg, Richard S. (1986), Computers and the Information Society. New York, NY: Wiley.

Rothman, Stanley and Mosmann, Charles (1976), Computers and Society. Chicago, IL: Science Research Associates. Inc.

Sandholtz, J. H., Rignstaff, C., and Dwyer, D. C. (1997), Teaching with Technology: Creating Student-Centered Classrooms. New York: Teachers College Press.

Schofield, Janet W. and Davidson, Ann L. (2002), Bring the Internet to School. San Francisco, CA: Jossey-Bass.

Shneiderman, Ben (2002), Leonardo's Laptop - Human Needs and the New Computing Technologies. Cambridge, MA: The MIT Press. 
Soloway, Elliot et. al. (2000), K-12 and the Internet, Communications of the ACM 43,1 (January, 2000), 19-24.

Spitzer, K. L., Eisenberg, M. B. Lowe, C. A., Information Literacy - Essential Skills for the Information Age, ERIC Clearinghouse on Information and Technology, Syracuse, New York, 1998.

Stoll, Clifford (1995), Silicon Snake Oil - Second Thoughts on the Information Highway. New York, NY: Anchor Books.

Twenty-First Century Workforce Commission. (2000), A Nation of Opportunity. National Alliance for Business, Washington DC (www.workforce21.org)

Weigel, Van B. (2002), Deep Learning for a Digital Age: Technology's Untapped Potential to Enrich Higher Education. San Francisco: Jossey-Bass. 